\title{
Presence of methicillin-resistant Staphylococcus aureus in slaughterhouse environment, pigs, carcasses, and workers
}

\author{
Meldra Ivbule ${ }^{1}$, Edvīns Miklaševičs ${ }^{2}$, Liene Čupāne ${ }^{2}$, \\ Laima Bērzinaa ${ }^{3}$, Andris Bālinš ${ }^{4}$, Anda Valdovska ${ }^{5}$ \\ ${ }^{1}$ Veterinary Surveillance Department, Food and Veterinary Service, Riga, LV-1050, Latvia \\ ${ }^{2}$ Institute of Oncology, Riga Stradins University, Riga, LV-1002, Latvia \\ ${ }^{3}$ Faculty of Information Technology, Latvia University of Agriculture, Jelgava, LV-3001, Latvia \\ ${ }^{4}$ Scientific Laboratory of Molecular Biology and Microbiology, \\ Latvia University of Agriculture, Jelgava, LV-3004, Latvia \\ ${ }^{5}$ Faculty of Veterinary Medicine, Latvia University of Agriculture, Jelgava, LV-3004, Latvia \\ Meldra.Ivbule@pvd.gov.lv
}

Received: November 14, 2016 Accepted: August 16, 2017

\begin{abstract}
Introduction: Methicillin-resistant Staphylococcus aureus (MRSA) is a highly resistant and difficult to cure zoonotic microorganism, which makes up a large part of food toxic infections and has shown high prevalence among pig population all over the world. The aim of the study was to establish the occurrence of MRSA in slaughterhouses, evaluate its antimicrobial resistance, and verify whether there are any differences or similarities with reference to other European countries. Material and Methods: A total of 100 pigs, 105 carcasses, 19 workers, and 24 samples from the environment of several slaughterhouses were examined by conventional microbial and molecular methods. Results: In total, 78 MRSA isolates were found. MRSA prevalence in slaughtered pigs varied from $8.0 \%$ to $88.6 \%$ depending on the slaughterhouse, reaching higher prevalence in slaughterhouses with higher slaughter capacity. In total, $21.1 \%$ of all workers were carriers of MRSA and $6.7 \%$ of carcasses were contaminated with MRSA. The $98.2 \%$ of MRSA isolates were resistant to penicillin, $89.1 \%$ to tetracycline, $60.1 \%$ to erythromycin, $65.5 \%$ to gentamycin, and 15 different spa types were found, among which spa type $t 01333$ was most widespread. Conclusion: The study indicated that MRSA prevalence and spa types differed according to slaughterhouse slaughter capacity and good hygiene practices. Quite high MRSA occurrence among slaughterhouse workers is one of the main factors which increase pork contamination risk.
\end{abstract}

Keywords: pigs, slaughterhouses, Staphylococcus aureus, antimicrobial resistance.

\section{Introduction}

Methicillin-resistant Staphylococcus aureus (MRSA) has been increasingly prevalent in pigs, veal, and pig farmers over the last decade (28). MRSA colonisation has recently been identified in people working with pigs, raising concerns about the role of pigs as reservoirs of MRSA for human infection.

MRSA is a multidrug-resistant Gram-positive bacterium, a critically important pathogen in human medicine. MRSA strains are resistant to all $\beta$-lactam antimicrobials through a penicillin binding protein (PBP2a) which has a low affinity to all $\beta$-lactams. The protein is encoded by the mecA gene, which resides on a mobile genetic element called a staphylococcal chromosomal cassette (SCCmec) lactams. Worldwide, the strains are resistant to a wide range of antibiotics. A subsequent worrying report indicated that $40 \%$ of pigs from Holland carried MRSA CC398 in their nostrils (8). This observation has been confirmed by a number of studies in other countries including Belgium (9), Denmark (13), Germany (32), USA (26), and Singapore (2). In Dutch abattoirs, 39\% (209/540) of pigs and $81 \%(44 / 54)$ of slaughter batches were MRSA positive in 2005-2006. The higher prevalence of MRSA in pigs in abattoirs compared with the prevalence on farms is evident (8). The occurrence of MRSA in food products and the role of food products 
in transmission of MRSA to humans are unknown. One of the debatable issues is whether carcasses obtained from MRSA-colonised pigs could cross-contaminate pork meat and be a source of human infections. Therefore, this study was undertaken to first describe the presence of MRSA in slaughterhouses, and to demonstrate the difference between slaughter techniques and slaughter capacity, as well as to verify which source is the most important for carcass contamination - human, animal, or environmental. The aim of the study was to determine the occurrence of MRSA in slaughterhouse environment, evaluate its antimicrobial resistance, and to establish whether there are any differences or similarities to other European countries.

\section{Material and Methods}

Slaughterhouses. During this study, samples were collected from four Latvian pig slaughterhouses (A, B, C, D) from October to March 2014. These slaughterhouses were of different pig slaughter capacity and were located in different areas of Latvia.

Slaughterhouse workers. The number of eligible workers per slaughterhouse was 5 to 10 . Slaughterhouses work only three to five days a week. The eligible population preferably included all workers, starting from the main slaughterline (lairage area, scalding/singeing and dehairing area, and evisceration area). Participants who agreed to take part in the study received one nasal swab and were asked to fill out a short questionnaire, which provided information about gender, age, current smoking habits, working area, contact with livestock outside the slaughterhouse, years of work experience in pig industry, and recent antimicrobial use. Written consent was obtained from all participants. Participants worked in various sections but primarily along the main slaughterline.

Slaughterhouse characteristics - production process. The layout of the slaughter process was similar, only differing by nuances. Upon arrival, live pigs were collected in the lairage area and only in slaughterhouse D pigs were showered with water shortly before stunning. In slaughterhouse B, all pigs were kept together in a building without heating on cement floor, without straw, water, and food for approximately 8 to $14 \mathrm{~h}$. During this period pigs were stressed and stereotypic behaviour was evident. Some pigs did not react to people, but squeaked and rocked head from side to side standing against cage grill.

The animals were stunned electrically and killed by bleeding after cutting the carotid artery. In slaughterhouse D, the pigs were showered with cold water to wash evident dirt from the skin. There were two types of dehairing methods. Slaughterhouses A and C used scalding method, slaughterhouse B - singeing, slaughterhouse D - depending upon customer's request - scalding or singeing method. After scalding in warm water $\left(65-69^{\circ} \mathrm{C}\right)$, carcasses were dehaired, flamed, and washed with water. In the evisceration line, the carcasses were opened, organs and fat were removed, and carcasses were cut in half along the entire length of the body. Subsequently, the heads were separated from the body and the carcasses were cooled at 7 to $4^{\circ} \mathrm{C}$.

All workers wore protective equipment, including jacket, trousers, hairnet, helmet, and rubber boots, and most of the workers directly involved in the slaughter process wore disposable gloves. Slaughterhouse B was the exception, as some workers there wore overalls, and others donned their own clothes. After leaving working areas, workers washed and disinfected their hands. Workers wore their work clothing during the break. At the end of the working day, slaughterhouse, all equipment, benches, and tables were cleaned and disinfected. All workers had access to facilities to wash their hands with warm water in all slaughterhouse areas. Two slaughterhouses (A and B) had low slaughter capacity (15-20 pigs slaughtered per day) and the other two (C and D) - high slaughter capacity (100-300 pigs slaughtered per day).

Sample collection. From each slaughterhouse, several samples were collected from workers, pigs, and the environment (Table 1). One swab from each worker was taken from both nostrils. Environmental samples were collected from tables, floors, equipment (surface samples, $\mathrm{n}=16$, collected using swabs), and air $(\mathrm{n}=8$, collected using Koch's sedimentation method). All microbiological samples were stored at $4{ }^{\circ} \mathrm{C}$ and the first isolation was performed within $24 \mathrm{~h}$ after sample collection. Nasal and rectal samples from pigs were taken after bleeding.

Table 1. Investigated samples in each slaughterhouse

\begin{tabular}{llllll}
\hline \multirow{2}{*}{ Sample type } & \multicolumn{5}{c}{ Slaughterhouses } \\
\cline { 2 - 5 } & $\mathrm{A}$ & $\mathrm{B}$ & $\mathrm{C}$ & $\mathrm{D}$ & Total \\
\hline Nasal samples & 25 & 15 & 25 & 35 & 100 \\
\hline Rectal samples & 25 & 15 & 25 & 35 & 100 \\
\hline Environment & 5 & 2 & 9 & 8 & 24 \\
\hline Carcasses & 25 & 15 & 25 & 40 & 105 \\
\hline Workers & 3 & 4 & 6 & 6 & 19 \\
\hline
\end{tabular}

Microbiological examination. Samples from swabs were transferred on Baird-Parker Agar (Becton, Dickinson, USA) and incubated at $37^{\circ} \mathrm{C}$ for $24 \mathrm{~h}$ according to LVS EN ISO 6888-1:1999 A1:2003 "Microbiology S. aureus and other species - Part 1: Technique using Baird-Parker agar medium performance". Coagulase positive samples with positive reaction on MSA plates were determined as S. aureus-like and were inoculated on CHROMagar Staph aureus plate (Becton Dickinson, USA) at $37^{\circ} \mathrm{C}$ for $24 \mathrm{~h}$. Isolates were confirmed to be $S$. aureus by examining previous tests. Samples were categorised as positive if at least one $S$. aureus positive colonyforming unit was isolated. Positive colonies from CHROMagar Staph aureus plate were inoculated on 
CHROMagar MRSA plate (Becton Dickinson, USA). Samples were categorised as positive if at least one MRSA positive colony-forming unit was isolated. These samples were categorised as MRSA-like and were stored at $-20^{\circ} \mathrm{C}$ until further use.

MRSA identification and spa typing. MRSA identification and further examination was performed in Riga Stradins University, Institute of Oncology and in LUA Laboratory of Molecular Biology and Microbiology. One suspected positive MRSA-like colony per sample was then confirmed by PCR and typed by spa typing.

Animals and humans were considered positive when MRSA was isolated and confirmed with multiplex-PCR from at least one anatomical sampling site. The dominant pig spa and SCC mec-type was defined as the type that was most abundantly present in pigs per slaughterhouse.

DNA was isolated by E.Z.N.A. Bacterial DNA Kit following manufacturer's instructions. DNA amount was verified by ND-1000 spectrophotometer. Polymerase chain reaction (PCR) was performed by HotStarTaq ${ }^{\circledR}$ Plus Master Mix Kit following manufacturer's instructions. The primer sequences for the mecA genes were: mecA F: 5'-GTAGAA ATGACTGAACGTCCGATGA-3' and mecA R: 5'CCAATTCCACATTGTTTCGGTCTAA-3'.

Amplification of DNA was performed in an Applied Biosystems 2720 thermal cycler using the following conditions: initial denaturation at $95^{\circ} \mathrm{C}$ for $5 \mathrm{~min}$ followed by 35 cycles of denaturation $\left(94^{\circ} \mathrm{C}\right.$ for $1 \mathrm{~min}$ ), annealing $\left(55^{\circ} \mathrm{C}\right.$ for $1 \mathrm{~min}$ ) and extension $\left(72^{\circ} \mathrm{C}\right.$ for $1 \mathrm{~min}$ ), followed by final extension at $72^{\circ} \mathrm{C}$ for $10 \mathrm{~min}$. The amplicons were separated using a $2 \%$ agarose gel. After electrophoresis, fragments were visualised by UV transilluminator and photographed for visual prove. $\mathrm{MecA}$ positive samples were 310 basis-pair-long. Spa typing was performed as described by Shopsin et al. (25). The spa gene typing was performed through the Ridom Spa server (www.spaserver.ridom.de).

Antimicrobial susceptibility testing. Randomly selected 57 MRSA positive samples from a total of 78 MRSA isolates were tested for antimicrobial susceptibility by disk diffusion method using Oxoid Antimicrobial Susceptibility Disks (Thermo Scientific, USA), following recommendations of Clinical and Laboratory Standards Institute (CLSI, USA) for inoculum preparation, inoculation, and incubation (5). The results were interpreted according to the information provided by Thermo Scientific instruction for each type of antibiotic discs. The following antimicrobial agents were tested: amoxycillin/ clavulanic acid (2:1 AMC; $30 \mu \mathrm{g})$, penicillin V (PV; $10 \mu \mathrm{g})$, oxacillin (OX; $1 \mu \mathrm{g})$, cephalexin (CL; $30 \mu \mathrm{g})$, ciprofloxacin (CIP; $5 \mu \mathrm{g})$, tetracycline $(10 \mu \mathrm{g} ; 30 \mu \mathrm{g})$, clindamycin (DA; $2 \mu \mathrm{g})$, erythromycin (E; $15 \mu \mathrm{g})$, gentamicin (CN; $10 \mu \mathrm{g})$, trimethoprim/ sulphamethoxazole 1:19 (Co-trimoxazole) (SXT; $25 \mu \mathrm{g}$ ), meropenem (MEM; $10 \mu \mathrm{g}$ ), and vancomycin (VA; 30 $\mu \mathrm{g})$. After $24 \mathrm{~h}$ of incubation at $37^{\circ} \mathrm{C}$, inhibition zones were measured in millimetres on the Mueller-Hinton agar plates (Oxoid, UK) and interpreted according to manufacturer's directions.

Data statistical analysis. Statistical analysis was conducted using software SPSS 16 (SPSS, INC., USA). The analysis of contingency tables based on statistics of chi-square test for independence was performed to determine whether there is a significant association between different slaughterhouses and pig dehairing methods. The Chi-square test was used to analyse whether the different slaughterhouses were related to $S$. aureus and MRSA prevalence. Hypotheses of independence were tested at significance level 0.05 . Cramér's V coefficient was used to measure the strength of the association between the variables as post-test after chi-square has determined significance. Cramer's V varies between 0 and 1 , showing little association between variables close to 0 and indicating strong association between variables close to 1 . Bayes's theorem was used to calculate probability to find staphylococcus in samples collected from infected pigs.

\section{Results}

Prevalence. In total, 78 MRSA strains were isolated from 348 samples (pigs after bleeding - 100 nasal samples, 100 rectal samples; 19 samples from slaughterhouse workers, 105 carcass samples, and 24 environmental samples) and 15 different spa types were identified among all MRSA isolates.

As shown in Fig. 1, microorganisms in pigs varied significantly $\left(\chi^{2} \mathrm{P}<0.05\right)$; S. aureus prevalence varied in slaughterhouses from $52.0 \%$ to $89.0 \%$, and MRSA prevalence from $8.0 \%$ to $88.6 \%$. A tendency linking the slaughterhouse capacity and the MRSA prevalence was observed, namely the higher the capacity of a slaughterhouse (pigs slaughtered per day), the higher the prevalence of microorganisms. The lowest prevalence of staphylococcus was observed in slaughterhouse A: S. aureus $52.0 \%$ and MRSA $8.0 \%$. The prevalence of $S$. aureus was similar in all slaughterhouses, except slaughterhouse D, but MRSA was more frequently found in slaughterhouses B and D.

MRSA prevalence in different slaughterhouses varied from zero to $24.0 \%$ in samples from carcasses and from $8.0 \%$ to $88.6 \%$ in samples from pigs after bleeding (Table 2). Positive environmental samples were found in slaughterhouse A (sample from scalding bath) and slaughterhouse $\mathrm{C}$ (slaughterhouse floor), but MRSA positive workers were detected in slaughterhouses $\mathrm{A}, \mathrm{C}$, and D. In addition, one human MRSA isolate $t 1255$ belonged to highly widespread antibiotic resistant types (Pen-Cef-Tetr and Pen-TetrClin-Ery-Ge-Tri), which belonged to MRSA isolates of pig origin. 
As seen in Fig. 2, 51\% of all pigs were MRSA positive. In $17 \%$ of all pigs only nasal samples were MRSA positive, in $20 \%$ - only rectal samples, but in $14 \%$ of all pigs - both nasal and rectal samples were MRSA positive. Data analysis revealed that MRSA and $S$. aureus positive sample distribution, which depended on sample source, was similar. Taking only nasal or rectal samples for MRSA testing decreased the probability to find a microorganism to almost $17 \%$ $20 \%$. According to Bayes's theory, the probability to identify a pig infected with MRSA by taking rectal samples is 0.67 and by nasal samples -0.61 ; the probability to detect a pig infected with $S$. aureus by taking only rectal samples is 0.69 , and by only nasal samples -0.65 .

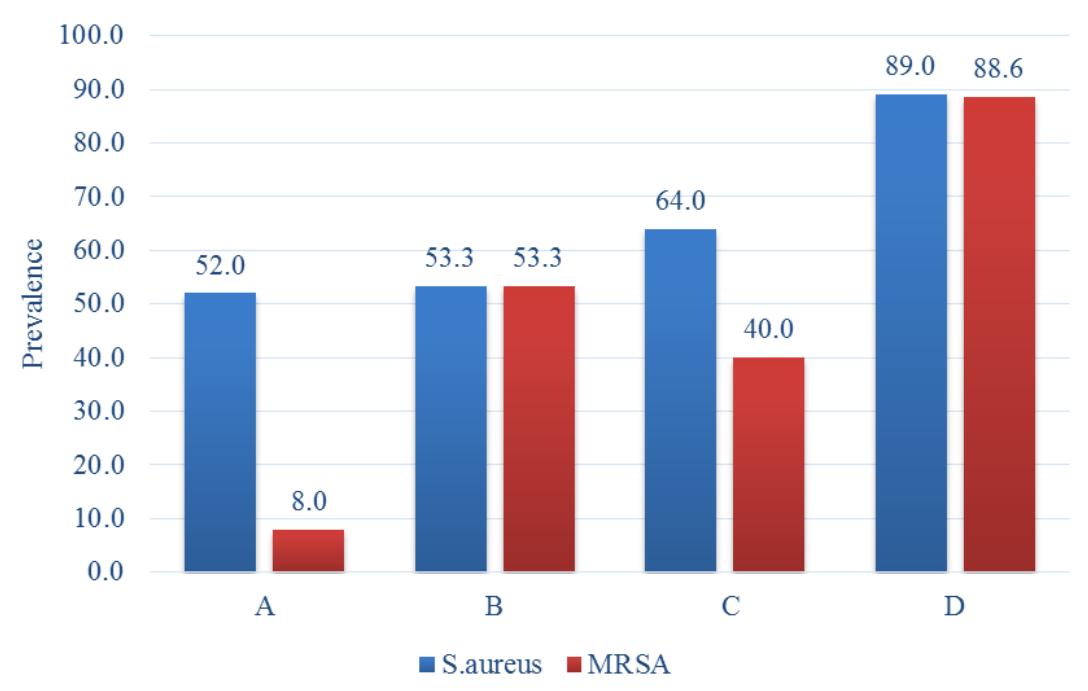

Fig. 1. Prevalence of staphylococcus in slaughterhouses

Table 2. MRSA prevalence in slaughterhouses

\begin{tabular}{lllllllll}
\hline Slaughterhouse & \multicolumn{2}{c}{ Pigs } & \multicolumn{2}{c}{ Carcasses } & \multicolumn{2}{c}{ Workers } & \multicolumn{2}{c}{ Environment } \\
\hline $\mathrm{A}$ & $2 / 25$ & $8.0 \%$ & $0 / 25$ & 0 & $1 / 3$ & $33.3 \%$ & $1 / 5$ & $20.0 \%$ \\
\hline $\mathrm{B}$ & $8 / 15$ & $53.3 \%$ & $0 / 15$ & 0 & $0 / 4$ & 0 & $0 / 2$ & 0 \\
\hline $\mathrm{C}$ & $10 / 25$ & $40.0 \%$ & $6 / 25$ & $24.0 \%$ & $2 / 6$ & $33.3 \%$ & $1 / 9$ & $11.1 \%$ \\
\hline $\mathrm{D}$ & $31 / 35$ & $88.6 \%$ & $1 / 40$ & $2.5 \%$ & $1 / 6$ & $16.7 \%$ & $0 / 8$ & 0 \\
\hline Total & $51 / 100$ & $51.0 \%$ & $7 / 105$ & $6.7 \%$ & $4 / 19$ & $21.1 \%$ & $2 / 24$ & 8.3 \\
\hline
\end{tabular}

Positive pigs - MRSA in both samples

Positive pigs -MRSA found only in rectal samples

Positive pigs -MRSA found only in rectal samples

Positive pigs - MRSA found only in nasal samples
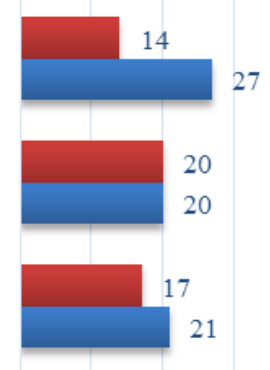

Positive pigs

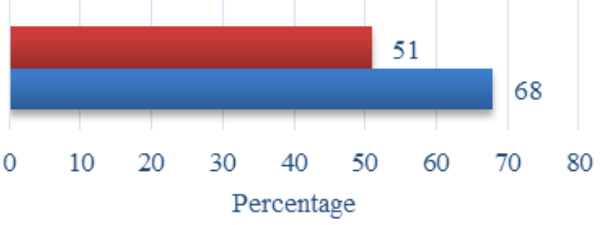

-MRSA $=$ S.aureus

Fig. 2. S. aureus and MRSA isolation from pigs depending on sample type. In slaughterhouse D, two sets of different MRSA spa types were isolated in two animals (spa type $t 337$ together with spa type $t 11744$ in one, and spa new type A together with spa type 111744 in the other) 
In total, 57 MRSA isolates with 14 different spa types (Tables 3 and 4) were recovered. Table 3 shows the MRSA distribution depending on spa type, sample origin, and resistance to several antibiotics. The number of different spa types was higher in slaughterhouses with greater pig production numbers (slaughterhouse D) and higher MRSA prevalence (slaughterhouse D). We established two spa types in slaughterhouse $A$, five in slaughterhouse $C$, three in slaughterhouse $\mathrm{B}$, and eight in slaughterhouse $\mathrm{D}$.
MRSA spa type t1333 (n = 15) was found in slaughterhouses C and D, spa type $t 011(\mathrm{n}=6)$ was found in slaughterhouses B and C, spa type $t 1250$ $(\mathrm{n}=2)$ was found in slaughterhouses $\mathrm{C}$ and $\mathrm{D}$, whereas other MRSA spa types were found only in one slaughterhouse. The most widespread spa types were $t 1333, t 337, t 11744$, and $t 011$. The analysis of MRSA strains revealed that spa types $t 1774$ and $t 337$ belonged to $S T 9$, and types $t 011$ and $t 808$ to ST398.

Table 3. MRSA origin

\begin{tabular}{|c|c|c|c|c|}
\hline Spa-type & Slaughterhouse & $\begin{array}{l}\text { Antibiotype } \\
\text { number }\end{array}$ & Antimicrobial resistance profile & Origin $(n)$ \\
\hline \multirow{6}{*}{ t011 } & \multirow{2}{*}{$\mathrm{C}$} & 4 & Pen-AmCl-Cef-Tetr & Slaughtered pig $(\mathrm{n}=1)$ \\
\hline & & 6 & Pen-AmCl-Cef-Tetr-Ery & Slaughtered pig $(n=1)$ \\
\hline & \multirow{4}{*}{$\mathrm{B}$} & 10 & Pen-Cef-Clin-Ery-Ge & Slaughtered pig $(\mathrm{n}=1)$ \\
\hline & & 26 & Pen-Tetr-Clin & Slaughtered pig $(\mathrm{n}=1)$ \\
\hline & & 28 & Pen-Cef-Tetr-Clin-Ery-Ge-Tri & Slaughtered pig $(\mathrm{n}=1)$ \\
\hline & & 30 & Pen-Cef-Cip-Tetr-Ary-Ge & Slaughtered pig $(\mathrm{n}=1)$ \\
\hline \multirow{10}{*}{$t 1333$} & \multirow{8}{*}{$\mathrm{C}$} & 1 & Pen & Slaughtered pigs $(n=2)$, carcass $(n=1)$ \\
\hline & & 7 & Pen-Am-Cef-Tetr-Clin-Ery-Ge & Carcass $(n=2)$ \\
\hline & & 19 & Pen-Tetr-Clin-Ery-Ge & Slaughtered pig $(\mathrm{n}=1)$ \\
\hline & & 20 & Pen-Tetr & Slaughtered pigs $(n=2)$, carcass $(n=1)$ \\
\hline & & 22 & Tetr-Clin-Ery & Slaughtered pig $(n=1)$ \\
\hline & & 23 & Pen-Cef-Tetr-Clin-Ery & Carcass $(\mathrm{n}=1)$ \\
\hline & & 25 & Pen-Tetr-Clin-Ery & Slaughtered pig $(\mathrm{n}=1)$ \\
\hline & & 28 & Pen-Cef-Tetr-Clin-Ery-Ge-Tri & Slaughtered pig $(n=1)$ \\
\hline & \multirow{2}{*}{$\mathrm{D}$} & 20 & Pen-Tetr & Slaughtered pig $(n=1)$ \\
\hline & & 19 & Pen-Cef-Clin-Ery-Ge & Slaughtered pig $(\mathrm{n}=1)$ \\
\hline \multirow{7}{*}{$t 337$} & \multirow{7}{*}{$\mathrm{D}$} & 14 & Pen-Cip-Tetr-Ery-Ge-Tri & Slaughtered pig $(\mathrm{n}=1)$ \\
\hline & & 15 & Pen-Cip-Trtr-Clin-Ery-Ge-Tri & Slaughtered pig $(\mathrm{n}=1)$ \\
\hline & & 17 & Pen-Tetr-Clin-Ery-Ge-Tri & Slaughtered pig $(\mathrm{n}=3)$ \\
\hline & & 18 & Pen-Tetr-Clin-Ery-Tri & Slaughtered pig $(\mathrm{n}=2)$ \\
\hline & & 19 & Pen-Tetr-Clin-Ery-Ge & Slaughtered pig $(\mathrm{n}=2)$ \\
\hline & & 20 & Pen-Tetr & Slaughtered pig (2) \\
\hline & & 1 & Pen & Slaughtered pig $(n=1)$ \\
\hline$t 808$ & $\mathrm{D}$ & 17 & Pen-Tetr-Clin-Ery-Ge-Tri & Slaughtered pig $(\mathrm{n}=1)$ \\
\hline$t 2451$ & $\mathrm{C}$ & 1 & Pen & Worker at slaughterhouse $(\mathrm{n}=1)$ \\
\hline \multirow{2}{*}{$t 899$} & \multirow{2}{*}{$\mathrm{A}$} & 1 & Pen & Slaughtered pig $(\mathrm{n}=1)$ \\
\hline & & 5 & Peb-AmCl-Tetr-Tri-Me & Slaughtered pig $(n=1)$ \\
\hline \multirow{6}{*}{$t 11744$} & \multirow{6}{*}{$\mathrm{D}$} & 10 & Pen-Cef-Clin-Ery-Ge & Slaughtered pig $(n=2)$ \\
\hline & & 17 & Pen-Tetr-Clin-Ery-Ge-Tri & Slaughtered pig $(n=1)$ \\
\hline & & 18 & Pen-Tetr-Clin-Ery-Tri & Slaughtered pig $(\mathrm{n}=1)$ \\
\hline & & 19 & Pen-Tetr-Clin-Ery-Ge & Slaughtered pig $(\mathrm{n}=1)$ \\
\hline & & 28 & Pen-Cef-Tetr-Clin-Ery-Ge-Tri & Slaughtered pig $(\mathrm{n}=1)$ \\
\hline & & 29 & Pen-Cef-Tetr-Clin-Ery-Ge-Tri-Me & Slaughtered pig $(\mathrm{n}=1)$ \\
\hline \multirow{2}{*}{$t 127$} & \multirow{2}{*}{$\mathrm{C}$} & 11 & Pen-Cef-Tetr & Carcass $(n=1)$ \\
\hline & & 20 & Pen-Tetr & Slaughterhouse floor $(n=1)$ \\
\hline \multirow{2}{*}{$t 1250$} & $\mathrm{D}$ & 17 & Pen-Tetr-Clin-Ery-Ge-Tri & Slaughtered pig $(\mathrm{n}=1)$ \\
\hline & $\mathrm{B}$ & 20 & Pen-Tetr & Slaughtered pig $(\mathrm{n}=1)$ \\
\hline \multirow{2}{*}{$t 2421$} & \multirow{2}{*}{$\mathrm{D}$} & 17 & Pen-Tetr-Clin-Ery-Ge-Tri & Slaughtered pig $(\mathrm{n}=1)$ \\
\hline & & 26 & Pen-Tetr-Clin & Slaughtered pig $(\mathrm{n}=1)$ \\
\hline$t 1255$ & $\mathrm{C}$ & 17 & Pen-Tetr-Clin-Ery-Ge-Tri & Slaughterhouse worker $(n=1)$ \\
\hline \multirow{2}{*}{$t 318$} & \multirow{2}{*}{$\mathrm{B}$} & 28 & Pen-Cef-Tetr-Clin-Ery-Ge-Tri & Slaughtered pig $(n=2)$ \\
\hline & & 29 & Pen-Cef-Tetr-Clin-Ery-Ge-Tri-Me & Slaughtered pig $(n=1)$ \\
\hline$t 421$ & $\mathrm{D}$ & 28 & Pen-Cef-Tetr-Clin-Ery-Ge-Tri & Slaughtered pig $(\mathrm{n}=1)$ \\
\hline new $A$ & $\mathrm{D}$ & 2 & Pen-AmCl-Tetr & Slaughterhouse worker $(\mathrm{n}=1)$ \\
\hline new $B$ & A & 27 & Pen-Cef-Tetr-Clin-Ery-Ge & Slaughterhouse worker $(\mathrm{n}=1)$ \\
\hline
\end{tabular}

* Pen - penicillin, AmCl - amoxicillin with clavulanic acid, Cef - cephalexin, Cip - ciprofloxacin, Clin - clindamycine, Ery - erythromycin, $\mathrm{Ge}$ - gentamycin, Me - meropenem, Tetr - tetracycline, Tri - trimethoprim/sulphamethoxazole, Van - vancomycin

Table 4. MRSA spa type distribution in slaughterhouses

\begin{tabular}{ll}
\hline Slaughterhouse & Spa types \\
\hline A & $t 899(\mathrm{n}=2)$, new B $(\mathrm{n}=1)$ \\
\hline C & $t 1333(\mathrm{n}=13), t 011(\mathrm{n}=2), t 2451(\mathrm{n}=1), t 127(\mathrm{n}=2), t 1255(\mathrm{n}=1)$ \\
\hline $\mathrm{B}$ & $t 011(\mathrm{n}=4), t 1250(\mathrm{n}=1), t 318(\mathrm{n}=3)$ \\
\hline $\mathrm{D}$ & $t 1333(\mathrm{n}=2), t 337(\mathrm{n}=12), t 808(\mathrm{n}=1), t 11744(\mathrm{n}=7), t 1250(\mathrm{n}=1), t 2421(\mathrm{n}=2), t 421(\mathrm{n}=1)$, newA $(\mathrm{n}=1)$ \\
\hline
\end{tabular}


Antimicrobial susceptibility testing of the selected MRSA isolates revealed the presence of 22 different antibiotic resistance profiles (ARPs). The distribution of MRSA spa type among the samples is shown in Table 5 and Figs 3 and 4.

The present study demonstrated that $26.3 \%$ of MRSA isolates belonged to spa type $t 1333(\mathrm{n}=15)$, and other most common spa types were $t 337(\mathrm{n}=12)$ and $t 11744(\mathrm{n}=7)$. Two to nine different ARP were detected among one MRSA spa type (Table 5). The most frequently occurring spa types showed the highest antibiotic resistance heterogeneity, for example spa type $t 1333$ belonged to nine ARPs (see Table 5), while the lowest heterogeneity was evident among MRSA spa type $t 318(\mathrm{n}=2)$.

MRSA isolate $t 1255$ that originated from a slaughterhouse worker also belonged to MRSA isolates from pig origin and had a highly widespread ARP Pen-Tetr-Clin-Ery-Ge-Tri. In total, 53\% of the isolates belonged to five most prevalent ARPs shown in Table 6.

Two most common ARPs $28.0 \%$ of all MRSA isolates) belonged to eight spa types. MRSA spa type t1333 was evident in ARP Pen-Tetr, Pen-Cef-TetrClin-Ery-Ge-Tri, Pen, and Pen-Tetr-Clin-Ery-Ge, but spa type $t 11744$ was evident in ARP Pen-Tetr-ClinEry-Ge-Tri, Pen-Cef-Tetr-Clin-Ery-Ge-Tri, and PenTetr-Clin-Ery-Ge. Nearly all MRSA isolates showed multidrug resistance.

The highest antimicrobial resistance was seen to five antibiotics $-24.6 \%$ of all MRSA isolates, six antibiotics $-19.3 \%$ of all MRSA isolates, and seven antibiotics $-15.8 \%$ of all MRSA isolates. Fewer isolates exhibited resistance to two (14.0\%), one $(10.5 \%)$, and three $(8.8 \%)$ antibiotics.

The $98.2 \%$ of all MRSA isolates were resistant to penicillin, $89.1 \%$ to tetracycline, $69.1 \%$ to erythromycin, $65.5 \%$ to clindamycin, $50.9 \%$ to gentamycin, $40.0 \%$ to trimethoprim/ sulphomethazole, $29.1 \%$ to cephalexin, $10.9 \%$ to amoxicillin combined with clavulanic acid, $9.1 \%$ to ciprofloxacin, and $3.6 \%$ to meropenem.

All isolates were sensitive to vancomycin, except six, which showed intermediate sensitivity to vancomycin: t011 ( $\mathrm{n}=1), t 2337(\mathrm{n}=2), t 11744$ $(\mathrm{n}=2), t 2421(\mathrm{n}=1)$.

Comparing MRSA spa type antibiotic resistance, it was found that even within the same spa type there were different ARPs, therefore the average percentage resistance was calculated from all MRSA isolates in one spa type. The results are shown in Fig. 4.

All five most common spa types in our samples differed from each other, but a shared tendency was seen, indicating that among all these types, almost $80 \%$ to $100 \%$ were resistant to tetracycline and penicillin. Spa type $t 1333$ was the most widespread from all spa types, but it had lower antimicrobial resistance in some samples showing resistance to seven antibiotics, while spa type $t 318$, which was the second most spread MRSA spa type, had the highest antimicrobial resistance among all MRSA spa types showing antimicrobial resistance to eight and seven antibiotics. Among all most common MRSA spa types, except t899, the majority was resistant to seven types of antibiotics (penicillin, tetracycline, cephalexin, clindamycin, erythromycin, gentamycin, trimethoprim/ sulphamethoxazole). MRSA resistance was observed even in the case of antibiotics which are not frequently used or are prohibited for use in food chain animal treatment, such as gentamicin and cephalexin. In some rare cases MRSA isolates showed resistance and intermediate sensitivity to meropenem and vancomycin (not shown in figures).

Table 5. Characterisation of the most frequently occurring MRSA spa types

\begin{tabular}{llll}
\hline Spa type & $\begin{array}{l}\text { All MRSA isolates } \\
(\%)\end{array}$ & The highest resistance to current antibiotics & $\begin{array}{l}\text { Total amount of different } \\
\text { antimicrobial resistance profiles }\end{array}$ \\
\hline$t 318$ & 5.3 & Cef, Gen, Ery, Clin, Tetr, Pen & 2 \\
\hline$t 011$ & 10.5 & Pen, Tetr, Cef, Am-Clav & 5 \\
\hline$t 11744$ & 12.3 & Ery, Clin, Tetr, Pen, Gen & 6 \\
\hline$t 337$ & 21.0 & Pen, Tetr, Ery, Clin & 7 \\
\hline$t 1333$ & 26.3 & Pen, Tetr, Ery, Clin & 9 \\
\hline
\end{tabular}

Table 6. Characterisation of most frequently found antibiotic resistance profiles (ARPs)

\begin{tabular}{llll}
\hline Most frequently found ARPs & $\begin{array}{l}\text { Number of MRSA } \\
\text { isolates }\end{array}$ & $\begin{array}{l}\text { All MRSA isolates } \\
(\%)(\mathrm{n}=57)\end{array}$ & $\begin{array}{l}\text { Number of different MRSA spa } \\
\text { types }\end{array}$ \\
\hline Pen-Tetr-Clin-Ery-Ge-Tri & 8 & 14.0 & $\begin{array}{l}6(t 337, t 808, t 11744, t 1250, \\
t 2421, t 1255)\end{array}$ \\
\hline Pen-Tetr & 8 & 14.0 & $4(t 1333, t 337, t 127, t 1250)$ \\
\hline Pen-Cef-Tetr-Clin-Ery-Ge-Tri & 6 & 10.5 & $\begin{array}{l}5(t 011, t 1333, t 11744, t 318, \\
t 421)\end{array}$ \\
\hline Pen & 4 & 7.0 & $4(t 1333, t 337, t 2451, t 899)$ \\
\hline Pen-Tetr-Clin-Ery-Ge & 4 & 7.0 & $3(t 1333, t 337, t 11744)$ \\
\hline
\end{tabular}




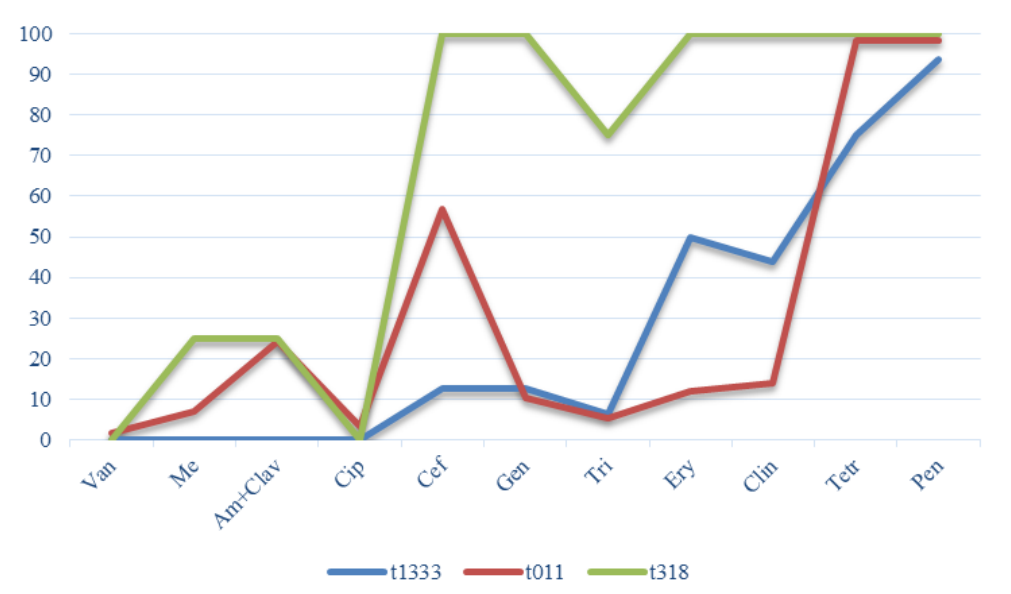

Fig. 3. Antimicrobial resistance of MRSA most common spa types: $t 1333$, $t 011$, and $t 318$

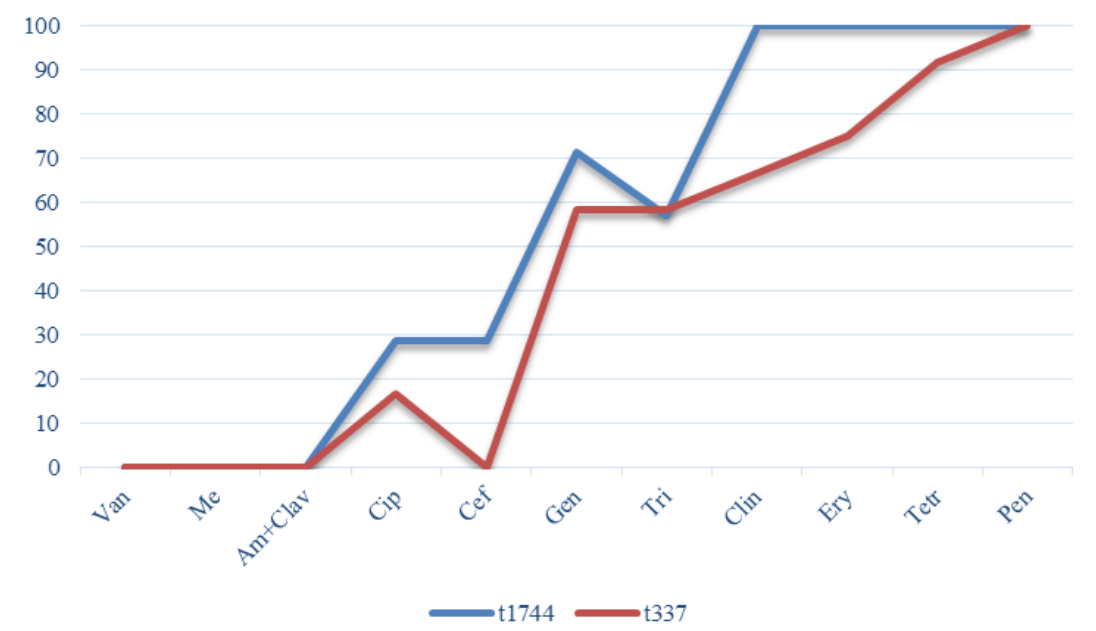

Fig. 4. Antimicrobial resistance of MRSA most common spa types: $t 1744$ and $t 337$

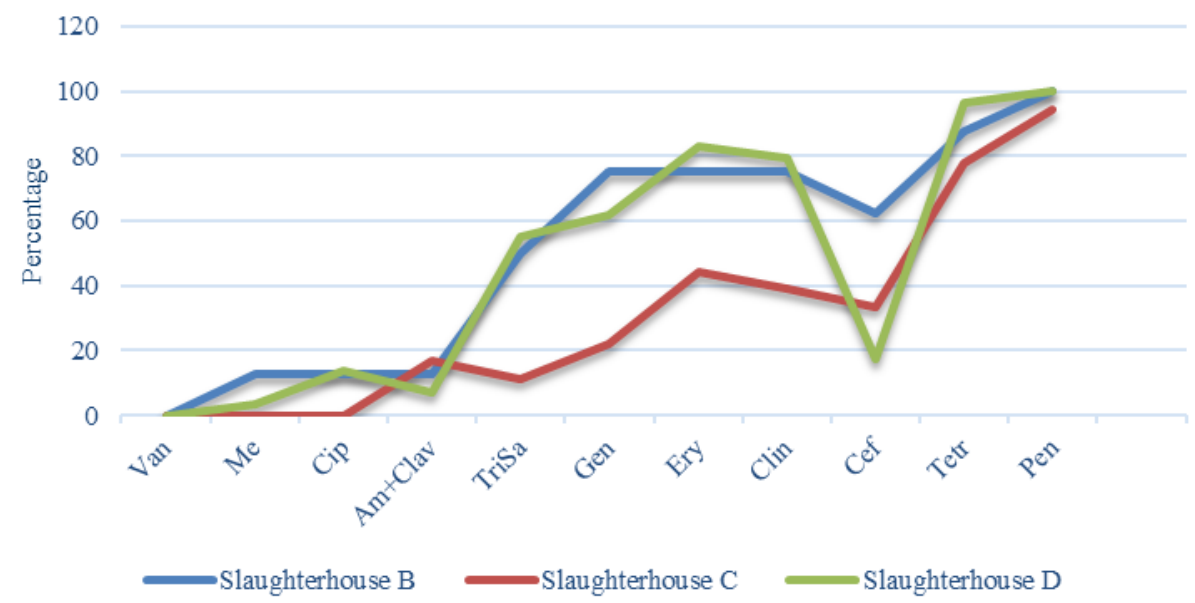

Fig. 5. Antimicrobial resistance of MRSA most common spa types by slaughterhouse

Comparing antibiotic resistance in slaughterhouses (Fig. 5), greater antibiotic resistance appeared to trimethoprim/sulphamethoxazole, gentamycin, and clindamycin in slaughterhouses $\mathrm{B}$ and $\mathrm{D}$, but in slaughterhouse $\mathrm{C}$ there was higher resistance to cephalexin. In slaughterhouse A (not shown in figure) three MRSA isolates were resistant to penicillin and two isolates were resistant to tetracycline. Samples 
from slaughterhouse A (one sample for each antibiotic) showed resistance to amoxicillin combined with clavulanic acid, trimethoprim/sulphamethoxazole, meropenem, cephalexin, clindamycin, erythromycin, and gentamycin. However, there was no evident difference in antibiotic resistance among slaughterhouses in relation to slaughter capacity.

The analysis of dehairing methods (singeing and scalding) revealed that there was no statistically significant difference (according to Fishers' test $\mathrm{P}>0.05$ ) between both methods regarding the influence on microorganism distribution on carcasses. S. aureus was isolated from carcasses treated with scalding method in $9.9 \%(\mathrm{n}=7)$ and MRSA in $7 \%$ $(\mathrm{n}=5)$, while in the case of singeing method $S$. aureus was isolated in $2.9 \%(\mathrm{n}=1)$ and no MRSA isolates were detected.

\section{Discussion}

This study investigated transmission and distribution of S. aureus and MRSA in individual pigs, slaughterhouse environment, and slaughterhouse workers. Significant findings included the identification and detailed characterisation of MRSA isolates from Latvian pigs, which was done for the first time. Furthermore, our study demonstrated MRSA colonisation status between pigs and carcasses. In addition, we evaluated the influence of the two types of pig dehairing methods in slaughterhouses with reference to their role in $S$. aureus prevalence, MRSA distribution, and antibiotic resistance level tendencies among different pig slaughterhouses depending on production efficiency. Presented research revealed that MRSA distribution and ARP depended on MRSA spa types. Antimicrobial contamination is one of the main factors in the emergence and transmission of MRSA in pigs and requires further investigation. The main reason for the contamination is close contact during the transportation or slaughterhouse procedures in confined spaces, which is consistent with the suggestions by Moodley et al. (17) and Broens et al. (3) that the likely source of MRSA transmission between farm pigs was the direct contact with their snout, skin, vagina, and faeces. Broens et al. (3) found that as many as $60 \%$ of previously MRSA negative pigs were positive at the stunning after transportation and holding (total time $3.75-16.5 \mathrm{~h}$ ) in slaughterhouse, after close contact with other pigs from different farms. Another, though less likely, source of MRSA for pigs in lorries and lairages may be the lorry drivers and/or abattoir personnel (3). Studies in pig slaughterhouses have shown MRSA prevalence of $5.6 \%$ among slaughterhouse workers and $22 \%$ among lorry drivers (28).

In addition, ARP, microarray, and MRSA spa types found in this study strongly support the view that in slaughterhouses with higher pork production the antimicrobial resistance is higher, and there is a greater
MRSA spa type heterogeneity. However, it was demonstrated that many factors, in addition to pig colonisation status in slaughterhouses, are likely to influence the carrier status. Such factors might include antibiotics used for treatment and prophylaxis, animal welfare condition, pig population density, and contact among them.

In our study MRSA was found only in two environmental samples (surface sample from slaughterhouse floor and a sample from scalding bath) and one $S$. aureus isolate from slaughterhouse A (from scalding bath), while other investigations have shown MRSA distribution in barn spaces. In Germany (11) MRSA prevalence was evident in 23 out of 27 investigated pig barns $(85.2 \%)$ and the prevalence in dust samples appeared to be $100 \%$; conversely, according to EFSA report (10) the prevalence in dust samples is $0 \%$. In previously mentioned studies testing dust and farm air, filtration methods and specific equipment (impingers, a six-stage Andersen air sampler) were used, but in our study Koch's sedimentation method was used, and it could be the reason for such a low MRSA detection level; however, it does not explain low MRSA prevalence in surface samples taken from slaughterhouses (tables, knives, gloves, floor, and pork boxes). This failure to detect airborne MRSA and S. aureus in slaughterhouses by means of Koch's sedimentation method did not guarantee the absence of these bacteria in the air. Dust is probably the main factor for MRSA distribution in the air since some surface and staff samples were also positive. MRSA evidence in the environment (air and surface samples) reveals the difficulties regarding the reduction of bacterial spread within the slaughterhouse.

Slaughterhouses should be strictly controlled to avoid contamination of healthy animals, carcasses, and workers by infected animals. Possible control measures could include the avoidance of pig contacts from different farms and new group forming, as well as effective vehicle and environment cleaning and disinfection and reducing antimicrobial use, especially for prophylactic purposes.

Burns et al. (4) found that more than $1 / 3$ of $S$. aureus isolates were resistant to tetracycline and erythromycin. Similar situation was observed in our study, where the resistance to tetracycline was $89.1 \%$ and to erythromycin $69.1 \%$. Moreover, $50.9 \%$ of isolates were resistant to gentamycin and $29.1 \%$ to cephalexin, which were not used for pig treatment in farms, but resistance to penicillin, which was used as the first choice antibiotic several years ago, and to tetracycline, which is administrated in high amounts in Latvia, reached $98.2 \%$ and $89.1 \%$.

Data similar to our study were present in Italian research (20) concerning antibiotic resistance profiles, where most MRSA isolates were multidrug-resistant, including resistance to clindamycin, tetracycline, and erythromycin. Study from Denmark (32) showed that spa type $t 034$ was most widespread, whereas in studies 
of Tenhagen et al. (27), Broens et al. (3), Crombe et al. (6), Friese et al. (11), Pletinckx et al. (23), and in our study spa type t1333, isolated from two slaughterhouses, was most frequently found. Other most widespread spa types were t337, t11744, and t011. MRSA t011 spa type was found in poultry farms in Belgium (19), Denmark (1), and Italy (20). Spa type t337 was found by Normanno et al. (20). According to Fisher's test value $\left(1.1 * 10^{-11}\right)$, statistically significant differences were found regarding the origin of the samples and MRSA spa types isolated from slaughterhouses. Spa type $t 1333$ was also one of the most frequently found MRSA spa types in the study by Tenhagen et al. (27) and it was also isolated together with $t 127$ by Agerso et al. (1). The results of our study are in agreement with the findings by Pletinckx et al. (23), who demonstrated different antimicrobial resistance profiles per spa type.

Human infections caused by MRSA are one of the main causes of morbidity and mortality in industrialised countries. In addition to the traditional routes of MRSA infection, it has recently been demonstrated that the direct transmission to humans takes place via contact with farm animals (31). Also, it is suggested that infection risk is created by handling of animal food products, for example raw meet (10).

Many studies on the prevalence of MRSA in farm animals and their carcasses have included pigs, which are currently the most important reservoir of MRSA (22). There are numerous reports on the prevalence of MRSA in various kinds of meats, especially in pork from Japan, Korea, Europe, and USA (21). The prevalence of MRSA in pigs and pig carcasses for human consumption is a public health issue, and the emergence of MRSA infections in humans has been well documented in several European countries (32). In several studies performed in slaughterhouses, MRSA prevalence in live pigs varied; e.g. in Dutch abattoirs $39 \%$ pigs and $81 \%$ slaughter batches were MRSA positive (8).

Our findings are in agreement with those reported by other researchers (20) and indicate that the risk of foodborne toxic infection linked to consumption of MRSA-contaminated meat is quite limited. Our study showed that during the slaughter process when high hygiene rules are applied, MRSA contamination decreased to zero in carcasses in relation to infected live pigs (prevalence $30 \%$ to $65 \%$ ). The high presence of MRSA in pigs is a potential professional hazard for staff working in the meat production chain (workers in farms and slaughterhouses, carriers, and veterinarians). It is known that people working several hours a week in direct contact with pigs infected with MRSA are exposed to high risk of nasal colonisation $(9,17,31)$. The general population shows a high prevalence (approximately 30\%) of S. aureus nasal colonisation, whereas MRSA nasal colonisation levels are lower $(0.7 \%-1.5 \%)$ depending on the geographical area (18). Human colonisation implies that carriers become a staphylococcal reservoir and may transfer the infection to others, or contaminate foods and food surfaces during handling. In addition, subclinical carriage of MRSA by humans is considered a risk factor for subsequent occurrence of clinical disease (15). MRSA from food-producing animals can be transferred to the slaughterhouse environment, and thus constitute a source of contamination for slaughterhouse personnel (31). In our survey, the anterior nares of 4 out of 19 investigated workers from pig slaughterhouses were colonised by MRSA, which is a substantially higher proportion when compared to other studies: in Italy 9 out of 113 (21), in Switzerland no MRSA in 179 slaughterhouse workers (14), in China no MRSA in 107 slaughterhouse workers (7), and in the Netherlands $5.6 \%$ of nasal carriage in 195 pig slaughterhouse workers (29). Similar results were reported by Gilbert et al. (12) in the Netherlands, who found that 11 of 341 pig slaughterhouse workers (3.2\%) were nasal carriers of LA-MRSA. In a Spanish study $14.3 \%$ of pig slaughterhouse workers were nasal MRSA carriers (16). High contamination with MRSA in barn or slaughterhouse may also be an issue of occupational health. It has been proven in several studies that humans working in pig farms and slaughterhouses carry MRSA of the same sequence type as swine (30). The presence of MRSA and $S$. aureus in the environment, carcasses, and worker nares is not surprising since the staff do not wear any respiratory masks and are in close physical contact with pigs. Moreover, their hands, gloves, equipment, clothes, and boots can serve as an infection transmitters and contaminants.

Antimicrobial resistance in human bacterial pathogens and zoonotic agents is growing worldwide, and this may threaten effective treatment of infections in humans. Multidrug-resistance was evident in our MRSA isolates. Nearly all isolates displayed resistance to two or more classes of antimicrobials and some of them were resistant or displayed intermediate sensitivity to vancomycin and meropenem. This indicates the development of resistance to previously mentioned antibiotics. These findings are in agreement with other studies on high MRSA prevalence and antimicrobial resistance in isolates from pigs, pork, and humans (2). As expected, $98.2 \%$ of isolates were resistant to penicillin and $89.1 \%$ to tetracycline, but quite a high resistance appeared to erythromycin $(69.1 \%)$, clindamycin $(65.5 \%)$, gentamycin $(50.9 \%)$, and trimethoprim/sulphamethoxazole $(40.0 \%)$. Several studies have shown similar resistance $(2,5)$. Pletinckx et al. (23) found high resistance to trimethoprim, lincomycin, and ciprofloxacin. Moreover, comparing the study by Tenhagen et al. (27) with our findings, it can be noted that antimicrobial resistance of MRSA t1333 spa type has increased. Tenhagen et al. (27) demonstrated that the most widespread spa type $t 1333$ was susceptible to methicillin, but in our study spa type t1333 showed high resistance to clindamycin (43\%), 
erythromycin $(50 \%)$, tetracycline $(75 \%)$, and penicillin $(93 \%)$.

Finally, it is known that MRSA prevalence and spa types differ depending on the slaughter capacity and good hygiene practice. The pigs used in our study originated from different slaughterhouses in our country, and this could be the reason for the wide heterogeneity of the MRSA spa types.

The presence of MRSA and S. aureus in carcasses intended for human consumption is a potential health hazard and it must be controlled by implementing personnel training on issues of biosecurity and food hygiene, throughout the meat chain from primary production to market. Another equally important fact is quite high MRSA occurrence among slaughterhouse workers, which also increases pork contamination risk. As far as we know, this is the first report documenting the prevalence and characteristics of MRSA in slaughterhouses and staff involved in pig industry in Latvia.

Conflict of Interests Statement: The authors declare that there is no conflict of interests regarding the publication of this article.

Financial Disclosure Statement: This study was funded by authors. The resources (materials, reagents) were financed from the authors' own means.

Animal Rights Statement: According to the Directive 2010/63/EU of the European Parliament and Council of 22 September 2010 on the protection of animals used for scientific purposes, there was no need for specific permission from competent authority, because the samples were obtained during the slaughter process after pig stunning and bleeding.

\section{References}

1. Agerso Y., Hasman H., Cavaco L.M., Pedersen K, Pederen K, Aarestrup F.M.: Study of methicillin resistant Staphylococcus aureus (MRSA) in Danish pigs at slaughter and in imported retail meat reveals a novel MRSA type in slaughter pigs. Vet Microbiol 2012, 157, 246-250.

2. Batisti A., Franco A., Merialdi G., Hasman H., Juresica M., Lorenzetti R., Feltrin F., Zini M., Aerestrup F.M.: Heterogeneity among methicillin-resistant Staphylococcus aureus from Italian pig finishing holdings. Vet Microbiol 2010, 142, 361-366.

3. Broens E.M., Graat E.A.M., Van Der Wolf P.J., Van De Giessen A.W., De Jong M.C.M.: Transmission of methicillin resistant Staphylococcus aureus among pigs during transportation from farm to abattoir. Vet J 2011, 189, 302-305.

4. Burns A., Shore A.C., Brennan G.I., Coleman D.C., Egan M., Fanning S., Galligan M.C., Gibbons J.F., Guttierrez M., Malhotra-Kumar S., Markey B.K., Sabirova J.S., Wang J., Leonard F.C.: A longitudinal study of Staphylococcus aureus colonization in pigs in Ireland. Vet Microbiol 2014, 174, 3-4.

5. Cockerill F.R., Wikler M.A, Alder J., Dudley M.N., Eliopoulos G.M., Ferraro M.J., Hardy D.J., Hecht D.W., Hindler J.A., Patel J.B., Powell M., Swenson J.M., Thomson R. B., Traczewski M.M., Turnidge J.D., Weinstein M.P., Zimm B.L.: Performance Standards for Antimicrobial Disk
Susceptibility Tests, edited by Clinical and Laboratory Standards Institute, Wayne, USA, 2012, pp. 11-13.

6. Crombe F., Willems G., Dispas M., Hallin M., Denis O., Suetens C., Gordts B., Struelens M., Butaye P.: Prevalence and antimicrobial susceptibility of methicillin-resistant Staphylococcus aureus among pigs in Belgium. Microb Drug Resist 2012, 18, 125-131.

7. Cui S., Li1 J., Hu1 C., Jin1 S., Li F., Guo Y., Ran L., Ma1 Y.: Isolation and characterization of methicillin-resistant Staphylococcus aureus from swine and workers in China. J Antimicrob Chemother 2009, 64, 680-683.

8. De Neeling A.J., Van Broek M.J., Spalburg E.C., Van SantenVerheuvel M.G., Dam-Daisz W.D., Boshuizen H.C., Van De Giessen A.W., Van Duijkeren F., Huijsdens H.W.: High prevalence of methicillin resistant Staphylococcus aureus in pigs. Vet Microbiol 2007, 122, 366-372.

9. Denis O. Suetens C., Hallin M., Catry B., Ramboer I., Dispas M., Willems G., Gordts B., Butaye P., Struelens M.J.: Methicillin-resistant Staphylococcus aureus ST398 in swine farm personnel, Belgium. Emerg Infect Dis 2009, 15, 1098-1101.

10. EFSA: Scientific opinion of the panel on biological hazards on requests from the European commission on assessment of the public health significance of the methicillin-resistant Staphylococcus aureus (MARSA) in animals and foods. EFSA J 2009, 993, 1-73.

11. Friese A., Schulz J., Hoehle L., Fetsch A., Tenhagen B.A., Hartung J., Roesler U.: Occurrence of MRSA in air and housing environment of pig barns. Vet Microbiol 2012, 158, 129-135.

12. Gilbert M.J., Bos M.E.H., Duim B., Urlings B.A.P., Heres L., Wagenaar J.A., Heederik D.J.J.: Livestock-associated MRSA ST398 carriage in pig slaughterhouse workers related to quantitative environmental exposure. Occup Environ Med 2012, $6,472-478$.

13. Guardbassi L., Stegger M., Skov R.: Retrospective detection of methicillin resistant and susceptible Staphylococcus aureus ST398 in Danish slaughter pigs. Vet Microbiol 2007, 122, 384-386.

14. Huber H., Koller S., Giezendanner N., Stephan R., Zweifel C.: Prevalence and characteristics of methicillin-resistant Staphylococcus aureus in humans in contact with farm animals, in livestock, and in food of animal origin, Switzerland, 2009. Euro Surveil 2010.

15. Jordan D., Simon J., Fury S., Moss S., Giffard P., Maiwald M., Southwell P., Barton M.D., Axon J.E., Morris S.G., Trott D.J.: Carriage of methicillin-resistant Staphylococcus aureus by veterinarians in Australia. Aust Vet J 2011, 89, 152-159.

16. Morcillo A., Castro B., Rodriguez-Alvarez C., Gonzalez J.C., Sierra A., Montesinos M.I., Abreu R., Arias A.: Prevalence and characteristics of methicillin-resistant Staphylococcus aureus in pigs and pig workers in Tenerife, Spain. Foodborne Pathog Dis 2013, 9, 207-210.

17. Moodley A., Lantronico F., Guardbassi L.: Experimental colonization of pigs with methicillin-resistant Staphylococcus aureus (MRSA): insights into the colonization and transmission of livestock-associated MRSA. Epidemiol Infect 2011, 139, 1594-1600.

18. Munckhof W.J., Nimmo G.R., Schooneveldt J.M., Schlebusch S., Stephens A.J., Williams G., Huygens .F, Giffard O.: Nasal carriage of Staphylococcus aureus, including communityassociated methicillin-resistant strains, in Queensland adults. Clin Micribiol Infect 2009, 15, 149-155.

19. Nemati M, K, Lipinska K., Denis U., Deplano O., Struelens M., Devriesa L.A., Pasmans F., Haesebrouck F.: Antimicrobial resistance of old and recent Staphylococcus aureus isolates from poultry: first detection of livestock-associated methicillinresistant strain ST398. Antimicrob Agents Chemother 2008, 52, 3817-3819.

20. Normanno G., Dambrosio A., Lorusso V., Samolis G., Taranto P., Parisi A.: Methicillin-resistant Staphylococcus aureus (MRSA) 
in slaughtered pigs and abattoir in Italy. Food Microbiol 2015 , $51,51-56$.

21. O'Brien A.M., Hanson B.M., Farina S.A., Wu J.W. Simmering, J.E., Wardyn S.E., Forshey B.M., Kulick M.E., Wallinga D.B., Smith T.S.L.: MRSA in conventional and alternative retail pork products. PLoS One 2013, 7, 30092.

22. Overesch G., Butner S., Rossano A, Perreten V.: The increase of methicillin-resistant Staphylococcus aureus (MRSA) and the presence of an unusual sequence type ST49 in slaughtered pigs in Switzerland. BMC Vet Res 2011, 7, 30.

23. Pletinckx L., Verhegghe M., Crombe F., Dewulf J., De Blecker Y., Rasschaert G., Butaye P., Goddeeris B.M., De Man I.: Evidence of possible methicillin-resistant Staphylococcus aureus ST398 spread between pigs and other animals and people residing on the same farm. Prevent Vet Med 2013, 109, 293-303.

24. Sergio D.M., Koh T.H., Hsu L.Y., Ogden B.E., Goh A.L., Chow P.K.: Investigation of methicillin-resistant Staphylococcus aureus in pigs used for research. J Med Microbiol 2007 6, 1107-1109.

25. Shopsin B., Gomez M., Montgomery S.O., Smith D.H., Waddington M., Dodge D.E., Bost D.A., Riehman M., Naidich S., Kreiswirth B.N.: Evaluation of protein A gene polymorphic region DNA sequencing for typing of Staphylococcus aureus strains. J Clin Microbiol 1999, 37, 3556-3563.

26. Smith T.C., Male M.J., Harper A.L., Kroeger JS., Tinkler G.P., Moritz E.D., Capuano A.W., Herwaldt L.A., Diekema D.J.: Methicillin-resistant Staphylococcus aureus (MRSA) strain
ST398 is present in Mildwestern, USA. Swine and swine workers. PLoS One 2009, 4, 4258.

27. Tenhagen B.A., Fetsch A., Stuhrenberg A.B., Schleuter G. Guerra B., Hammerl J.A., Hertwig S., Kowall J., Kampe U., Schroeter A., Braunig J., Kasbohrer A., Appel B.: Prevalence of MRSA types in slaughter pigs in different German abattoirs. Vet Rec 2009, 165, 589-593.

28. Van Cleef B.A.G.L., Verkade E.J.M., Wulf M.W.H., Buiting A.G., Voss A., Huijsdens X.W., Van Pelt W., Mulders M.N., Kluytmans J.A.J.W.: Prevalence of livestock associated MRSA in communities with high pig-densities in the Netherlands. PlosOne 2010, 5, 9385.

29. Van Cleef B.A.G.L., Broens E.M., Voss A., Huijsdens X.W., Zuchner L., Van Bethem B.H.B., Kluytsmans J.A.J.W., Mulders M.N., Van De Giessen A.W.: High prevalence of nasal MRSA carriage in slaughterhouse workers in contact with live pigs in the Netherlands. Epidemiol Infect 2010, 138, 756-763.

30. Van Den Broek I.V., Cleef B.A., Haenen A., Broens E.M., Van Der Wolf P.J., Van Den Broek MJ., Huijsdens X.W., Kluytsmans J.A., Van De Giessen A.W., Tiemersma E.W.: Methicillin-resistant Staphylococcus aureus in people living and working in pig farms. Epidemiol Infect 2009, 137, 700-708.

31. Wendlandt S., Schwarz S., Silley P.: Methicillin resistant Staphylococcus aureus: food-borne pathogens? Ann Rev Food Sci Technol 2013, 4: 117-139.

32. Witte W., Strommenger B., Stanek C., Cunny C.: Methicillinresistant Staphylococcus aureus ST398 in humans and animals. Emerg Infect Dis 2007, 13, 255-258. 